Outcome evaluation of a multi-disciplinary community-based continence service for Australian women

Submitted to Women and Health

by

Winsome St John \& Marianne Wallis

Dr Winsome St John PhD, RN, RM, MCHN, BAppSc, GradDipEd, MNS, FRCNA

Research Centre for Clinical Practice Innovation

PMB 50 Gold Coast Mail Centre

Queensland Australia 9726

Phone Work 61755528935

Phone Home 61755940514

Fax 61755528526

w.stjohn@griffith.edu.au

Associate Professor Marianne Wallis PhD, RN BSc(Hons), Cardio Thoracic Cert. MRCNA

Research Centre for Clinical Practice Innovation

Chair, Clinical Nursing Research

Griffith University and Gold Coast Health Services District

108 Nerang Street

Southport

Queensland Australia 4215.

Submitted March, 2004

This was a collaborative project with the Gold Coast Health Service District, Queensland Health. It was funded under the Department of Health and Ageing, National Continence Management Strategy, Innovative Grants program. 
Outcome evaluation of a multi-disciplinary community-based continence service for Australian women 


\title{
Outcome evaluation of a multi-disciplinary community-based continence service for
}

\section{Australian women}

\begin{abstract}
This longitudinal study evaluated the effectiveness of a multi-disciplinary community-based service offering conservative treatment for Australian women suffering urinary incontinence and living independently in the community, in terms of urinary incontinence symptom severity, impact on quality of life and knowledge outcomes. One hundred and twenty-three women attending The Waterworx Centre, a multi-disciplinary, publicly funded community-based continence service in South East Queensland Australia participated in the study. They received multi-disciplinary conservative treatment for urinary incontinence, including comprehensive assessment and an individually-tailored plan of care. All the women were also linked back to their own generalist health professional for ongoing care and management.
\end{abstract}

Data were collected over a one-year period: at first consultation, and at three months and six months following the first consultation. The International Continence Society Urinary Symptom Index Short Form - Female Outcome was used to measure urinary symptoms and impact on quality of life, and a researcher-developed test was used to measure changes in knowledge.

Results showed that the women experienced an improvement in urinary symptoms and continence-related knowledge at three months following first consultation, and a decreased impact on quality of life, with these improvements either being sustained or increasing at six months. This study demonstrated that multi-disciplinary community-based services offering specialist conservative treatment for women suffering urinary incontinence can be effective in achieving improvements in urinary symptoms and continence-related knowledge and reducing the impact of urinary incontinence on quality of life. 


\section{Outcome evaluation of a multi-disciplinary community-based continence service for women}

\section{Introduction}

Over two million community-based Australians are estimated to suffer urinary incontinence, including approximately 1.8 million (19.3\%) women (Chiarelli et al., 2001). Based on a metaanalysis of international studies, Chiarelli et al. estimated the prevalence of urinary incontinence in community-based women as $16.5 \%$ in women younger than 40 years, $20.9 \%$ at $40-49$ years, rising to $28.4 \%$ at 80 years and older. Chronic urinary incontinence can persist for many years. It has been found to impact on health status (Roe \& Doll, 2000; Johnson et al., 1998), social activities (Fultz \& Hersog, 2001; Peake \& Manderson, 2003), psychological status (Dugan et al., 2000; Meade-D'Alisera et al., 2001; Burgio et al., 2001) and quality of life (Wyman, 1998; Swithinbank \& Abrams, 1999; Liberman et al., 2001). Although there have been many advances in surgical and medical approaches to treatment, it is generally considered that behavioural / conservative management, such as treatment of contributing or exacerbating conditions, pelvic floor exercises, toileting techniques and social management, should be the first line of treatment for urinary incontinence (American Medical Directors Association, 2001; Sampselle, 2000).

Many studies have demonstrated improvements in urinary incontinence symptoms following conservative or behavioural interventions. Continence nurse-led interventions have been found to be effective (McGhee et al., 1997; Williams et al., 2000; Borrie et al., 2002). Lewey, Billington, and O'Hara (1997) undertook a long-term follow-up of 89 women aged 18-92 years attending a nurse-led continence clinic offering conservative treatments, finding that $54 \%$ reported being symptom-free up to three years following discharge. Improvements in urinary incontinence have been found from interventions such as behavioural therapies, bladder and pelvic floor exercises and re-training (O'Brien, et al., 1991; Seim, et al., 1996; Publicover and Bear, 1997; McDowell et al., 1999; Sampselle, 2000), with pelvic floor exercises resulting in improvements maintained over a six month period in elderly women (Burns et al., 1993). Burgio et al. (2001) found that improvements in urinary incontinence symptoms resulted in improvements in psychological symptoms, particularly for clients receiving behavioural interventions. 
Many of these studies involved mixed gender, home-bound or elderly sample groups, with few studies investigating older and younger, independent-living, community-dwelling women, particularly within an Australian context. Some studies have focussed on single interventions, such as pelvic floor exercises, however, it is usual for continence care and management to use a range of approaches concurrently. While some studies have examined outcomes of services provided by continence nurse specialists, none have examined the impact of undertaking comprehensive assessment and management utilising a multi-disciplinary approach with linkages between disciplines. Rather than examine the impact of specific interventions, it was considered important to evaluate the impact of offering a comprehensive model of care.

\section{Research Design and Method}

The aim of this study was to evaluate urinary incontinence symptom severity, impact on quality of life and knowledge outcomes for women after attending The Waterworx Centre, a multidisciplinary community-based service offering behavioural / conservative treatments and therapies. This study incorporated a longitudinal pretest-posttest design. Data relating to urinary incontinence symptoms and client knowledge were collected by questionnaire and chart audit at first consultation and then at three and six months following the first consultation. This study was approved by the ethics committees of the university and the health service district involved.

\section{Setting, Recruitment and Intervention}

During the study period, The Waterworx Centre was located within the community health service of the publicly funded Gold Coast Health Service District, Queensland Australia. The Gold Coast City is one of the fastest growing in Australia, and is a major tourist destination, incorporating both rural and urban areas. The city is the second fastest growing local government area in Australia (Gold Coast City Council, 2004), with a population of 455,473 in 2003 (Australian Bureau of Statistics, 2003). It has a high intra-Australian and international migration into the area, with many older people choosing to retire to the region.

The Centre aimed to provide short-term specialist assessment and advice to people living independently in the community suffering urinary incontinence, then to link them back to generalist health practitioners for ongoing care and management. The Centre was promoted to health professionals and the public in the region via patient pamphlets, health professional Community-based continence care for women 
pamphlets, posters, community talks and media stories. The Centre accepted self-referrals, together with referrals from medical practitioners, medical specialists, physiotherapists, community nurses, and on discharge from hospital. Criteria for admission to the study were the same as those for admission to the Centre: that clients suffered urinary incontinence, lived independently in the community and did not suffer dementia. All women attending the Centre between March 2001 and February 2002 were informed about the project and invited to participate when they inquired about services and made their first appointment. Those agreeing to participate in the study signed a consent form prior to their first appointment.

Services provided were based on the Waterworx model (St John, et al., 2004, in press), which focuses on community-based conservative/behavioural treatments and therapies for urinary incontinence; emphasises expert multi-disciplinary care, inter-disciplinary collaboration and linkages; and promotes easy client access (St John, Wallis, \& James, 2002). Clients had access to comprehensive assessment, conservative treatment, management, education, support and referral. The Centre, staffed by continence specialist nurses and physiotherapists, had strong links to local generalist health practitioners and the local public hospital.

Because of the multi-causal nature of urinary incontinence and the individualised nature of clients' social contexts, attitudes and circumstances, care provided by the Centre was individualised, multi-dimensional and targeted a range of factors, rather than being driven by single protocols and clinical pathways. At the first appointment, which took approximately an hour, a specialist continence nurse and/or physiotherapist undertook a comprehensive assessment. The assessment included a client interview focused on urinary symptoms, medical history, social history, social impact of urinary incontinence, current strategies for addressing urinary incontinence, goals for attending the Centre, and a physical examination, including pelvic floor strength and endurance (where appropriate). Urinary symptoms were assessed using the International Continence Society Urinary Symptom Index Short Form - Female (ICS USI-SF-F) (described below), a bladder diary and (where appropriate) a 24 hour pad test. Through linkage to a local medical practitioner investigations were carried out where they were clinically indicated, including: residual urine, mid-stream urine (for micro-biological studies) and urodynamics. Individualised evidence-based conservative management and treatment included continence-related education and advice about their incontinence condition, fluid management, Community-based continence care for women 
food and fluids likely to exacerbate incontinence, medication education, hygiene and skin care, sexuality, supports and treatments for improved mobility, bladder training for urge incontinence, pelvic floor re-training/re-education exercises, toileting techniques for complete emptying of the bladder, bowel management to minimise constipation, appropriate continence aids for their condition, and information about management of urinary incontinence in social situations. Clients requiring further assessment, intervention and/or access to support for continence aids were referred as appropriate.

As general medical practitioners and / or health practitioners are responsible for providing ongoing health care, it was considered important to develop structured links with them. A linkage letter was mailed to all clients' general medical practitioners (GP) and/or health practitioners, informing them of clients' ongoing care and management and providing them with information about incontinence. Subsequent appointments at the Centre, of about 15-20 minutes, addressed ongoing progress with therapies, on an individual basis. Clients could attend as many appointments at the Centre as they considered useful in relation to their individual needs, for a period of up to six months. During the project period, in addition to the individual consultations, all Centre clients were invited to group sessions conducted by Centre staff every 1-2 weeks. These sessions focussed on pelvic floor exercises and 'refresher' information, aiming to consolidate the advice and education provided in individual consultations.

\section{Instruments and Measures}

Data were gathered at three collection points: at first appointment (T1), and at three (T2) and six (T3) months following first appointment. Incontinence symptom severity and impact on quality of life were measured using the ICS USI-SF-F. Client knowledge was assessed using a researcher-developed knowledge test.

The ICS USI-SF-F was chosen because it has been developed with the expressed intention of characterising severity for lower urinary tract symptoms, impact on quality of life and to evaluate treatment outcomes (personal communication Donovan, 2001; Jackson et al., 1996). Originally based on the International Continence Society Urinary Symptom Index - Male questionnaire, it was developed specifically for women as an extensively tested long form with 33 items (Jackson et al., 1996). A short form of the questionnaire has been developed with 19 items 
using Likert-type scale responses, divided into five sections: incontinence symptoms, voiding, filling, sexual symptoms and impact on quality of life (personal communication, Donovan 2001) (see Table 1). Reliability data from other studies are not yet available on this short form of the instrument. In this study the Cronbach alpha scores for the various sub-scales, measured at the initial data collection point, ranged from $0.52-0.88$ (See Table 2).

Changes in continence-related knowledge were evaluated using a researcher-developed knowledge test. The test consisted of 17 multiple-choice items based on current knowledge about urinary incontinence related to fluids, urinary tract infections, toileting habits, exacerbating conditions and bladder function. Each question was given one point, and results were totalled to give a score out of 17 .

\section{Data Collection}

Participants were mailed the ICS USI-SF-F to complete at home prior to attending their first appointment. The knowledge test was completed immediately prior to their first consultation, administered by a research assistant who was not a health professional. Demographic information and client history information were gathered via chart audit using a researcherdeveloped audit tool. Not all participants attended at the three and six month data collection points. Subsequent non-attenders were mailed ICS USI-SF-F and asked to return the questionnaire in a pre-paid envelope, receiving two phone reminders and a further copy of the questionnaire if they failed to return it.

\section{Data analysis}

All data were entered into the computer program SPSS. Descriptive univariate statistics were calculated on all demographic data. Cronbach's alphas were calculated on the sub-scales of the ICS USI SF-F. Repeated measures ANOVA were calculated for the data relating to outcome measures. An initial analysis was conducted with no covariates. Following this, the ANOVA was recalculated, controlling for age group (above and below 65 years) and duration of incontinence symptoms prior to attending the Centre. The age of 65 years was chosen as a cutoff because this is the normal retirement age for women in Australia, and most continence services are provided to women above 65 years via the Federal Home and Community Care 
(HACC) program funding. In addition, a further ANOVA was calculated with the number of The Waterworx Centre attendances used as a co-variate.

As there was large loss to follow-up encountered in this study, Student's t-test analysis was used to determine whether there were differences between the subjects who only completed the initial data collection and the subjects who completed follow-up data collection. Due to the large number of non-responses to the sexual subscale of the USI-SF-F, a crosstabulation of sexual sub-scale response with age group and chi square analysis was undertaken.

\section{Results}

\section{Description of Participants}

Of 178 eligible women who attended the The Waterworx Centre during the project period, 123 (69\%) gave consent and agreed to participate in the project, completing the ICS USI-SF-F and the knowledge test at $\mathrm{T} 1$. The mean age of participants was 63.9 years ( $\mathrm{sd}=12.2$; range 33-88 years). All study participants attended a first appointment at the Centre, however, the number of attendances at subsequent appointments varied. The average attendance was three visits (mean=3.37; sd 1.8; range 1-9).

Table 3 provides a summary of demographic data, type of incontinence suffered and previous care for incontinence for all participants in the study. Approximately half the participants were aged 65 years or younger, and most had suffered urinary incontinence for many years (mean 9.1 years; sd=12.6; range 1 month to 70 years), experiencing mostly urge and stress incontinence. None experienced reflex or functional urinary incontinence. They had a range of educational backgrounds, were mostly retired, Australian born, and either living with a partner or alone. Of the 123 participants, less than half had received any previous care for their urinary incontinence (Table 3). Of those who had received care, most had seen medical practitioners or a medical specialist. Few had seen a continence specialist about their urinary incontinence, particularly continence nurse specialists or physiotherapists. Over half of the participants reported a range of co-morbidities (See Table 4). Nearly $46 \%$ of the female participants had undergone a hysterectomy and over $20 \%$ had previously had a pelvic floor or bladder repair. 


\section{Comparison Between Completers and Non-Completers}

There was a large loss to follow-up in this study. Some participants did not wish to complete any of the follow-up surveys and some completed parts of the questionnaire but left some answers blank, particularly questions in the sexual symptoms subscale of the ICS USI-SF-F. Consequently the responses of only 63 subjects are reported in the outcome measures for this paper. Because of the large loss to follow-up, comparisons were made between those who only completed initial data collection and those who completed follow-up data collection. This analysis indicated that there were no statistically significant differences between the two groups with regard to duration of symptoms, scores in the initial knowledge test and all the subscales of the urinary symptoms index (See Table 5). However, the group that did not complete data collection were, on average, younger and made fewer visits to The Waterworx Centre (appointments and classes). Non-completion of the sexual sub-scale of the USI-SF-F decreased with increasing age. Table 6 shows that $87.5 \%$ of respondents under $50,54 \%$ of those aged $50-69$ years and only $15.9 \%$ of those over 70 years completed the sexual symptoms sub-scale. The differences between the groups reached statistical significance (chi square (df) $=28.8(2) ; p<0.0001)$.

\section{Outcome evaluation}

For the participants who completed data collection at all three times, analysis revealed that, following attendance at The Waterworx Centre, there was an improvement in all subscales of the urinary symptom index, except for the sexual symptoms subscale, and there was an improvement in knowledge, and this improvement was maintained over time (See Table 7 and Figures 1 and 2).

When covariates were added to the analysis it became clear that age group, duration of symptoms prior to attending the Centre, and number of visits to the Centre did not influence the improvements in symptoms. The number of attendances when included as a covariate generated one statistically significant difference over time and that was in the sexual symptoms subscale $\left(F_{2,22}=6.2 ; p=0.005\right)$. 


\section{Discussion}

The model of service delivery being evaluated in the study provided the basis for comprehensive continence care provision. The model featured services and care that were: provided by a multi-disciplinary team of continence specialist nurses and physiotherapists linked to medical practitioners; community based; targeted women living independently in the community; and was attentive to the development of linkages between specialist and generalist health professionals. This study has confirmed that conservative multi-disciplinary management of urinary incontinence for community-based women results in improvements in symptoms, reduces the impact on quality of life, and improves knowledge in an Australian, communitybased cohort of women. These findings were applicable, regardless of age or duration of symptoms prior to attending the Centre. The only symptom sub-category of the ICS USI-SF-F that did not demonstrate improvement was Sexual, which did not demonstrate statistically significant changes over time. When the co-variate of number of clinic visits was introduced there was a significant decrease following Centre attendance. However, these data should be treated with caution, as there was a large amount of missing data for the Sexual subscale. Non-completion was found to increase with age (Table 6), however, it was unclear whether this lack of reporting related to embarrassment, not being sexually active, or to not having a sexual partner. As sexuality is an important area of health and wellbeing, this area should be investigated further, perhaps using different methods, examining the impact of age more closely and using a more refined tool.

Variation in the number of times each participant attended The Waterworx Centre was an important issue arising from the conduct of the project. All participants attended the first appointment, however, many participants did not return for further appointments, while others continued to attend for six months. Although the women were able to choose the number of times they attended the Centre, there was no significant difference between those attending more often and those attending less often. A range of personal and/or clinical factors could explain this finding including: one appointment was all that was required to gain the information and support they needed, services were not appropriate to needs, or personal circumstances prevented them from attending. Whatever the reason for this finding, this study suggests that conservative, multi-disciplinary, community-based, specialist continence services should be provided on a time-limited or consultative basis, and supports linking clients back to generalist 
health practitioners for ongoing care and management. The variation in attendance also points to the importance of tailoring care plans to individual physical, emotional and learning needs; underlines the multi-factorial causes of urinary incontinence; the necessity for creating better communication links with generalist health professionals; and the need to provide women with expert advice to empower them to manage their own condition.

Several issues from the findings of this study are striking. Despite having suffered from urinary incontinence for many years, it was disturbing that many of these women had never consulted a health practitioner about their urinary incontinence and few had consulted a specialist continence practitioner prior to attending The Waterworx Centre. This lack of access is particularly important given the improvements demonstrated and maintained over time in symptoms and knowledge, and the reduced impact on quality of life. It points to a need to investigate reasons why sufferers do not access generalist or specialist services for their urinary incontinence, and the importance of promoting the availability, nature and effectiveness of specialist continence services. The broad applicability of this multi-disciplinary model of service for older and younger women, together with women who had suffered urinary incontinence for many years or more recently is particularly important for informing appropriate planning and targeting of community-based services.

\section{Limitations of Study}

These results relate to The Waterworx model of service delivery, and should not be applied to other groups of clients or services that do not have the characteristics of this model of service delivery. Differences in the nature of urinary problems experienced by different client groups, the expertise of staff and the nature of services may result in different outcomes.

This study used a pretest-posttest design rather than a randomised controlled trial, because the benefits of conservative management over no treatment for urinary incontinence is well established and it was not deemed ethical to leave one group untreated. Using the waiting list to establish a control group was also not possible, because this was a new service without an established waiting list. The nature of urinary incontinence and its social stigma causes difficulties in designing and conducting rigorous studies. Perusal of the literature demonstrates that there is often difficulty in obtaining large or random sample sizes for studies related to Community-based continence care for women 
urinary incontinence in community-dwelling populations. The nature of urinary incontinence and care provision contribute to a lack of a control, problems of missing data related to attrition (Williams, et al 2000), small sample size (Publicover \& Bear, 1997), and poor return rate (Lewey et al., 1997). Thus, this was the most rigorous but pragmatic design possible.

Because a convenience sample was used, results of this study should be interpreted with caution. However, although participants' responses to treatment could not be compared with untreated controls, the two follow-up data collection points allow for an estimation of the longterm effect of treatment. Further, consistent with prevalence data from the literature (Chiarelli, Bower, Wilson, Sibbritt, \& Attia, 2001), this convenience sample of all of the women attending the Centre during a specified period included both younger and older community-dwelling women.

While it is difficult to design and carry out rigorous research into continence outcomes it is, never-the-less, important to continue to evaluate the effectiveness of models of care, management and treatments of urinary incontinence, in a range of contexts.

\section{Conclusion}

This study adds to previous research by confirming that conservative management leads to symptom and knowledge improvements, and a reduction of the impact on quality of life in women living independently in the community. The conservative management and treatments offered by The Waterworx Centre using specialist multi-disciplinary approaches and close links with generalist health practitioners resulted in statistically and clinically significant improvements in urinary symptoms and continence-related knowledge in community-dwelling women suffering urinary incontinence. These results support the development of specialist multi-disciplinary community-based services for women. 
Table 1: $\quad$ International Continence Society, Urinary Symptom Index, Short Form Female: Questionnaire and subscales

\begin{tabular}{l}
\hline Question \\
\hline Subscale 1: Urinary symptoms \\
\hline Does urine leak before you can get to the toilet? (Q4) \\
How often do you leak urine? (Q6) \\
Does urine leak when you are physically active, exert yourself, cough or sneeze? (Q7) \\
Do you ever leak urine for no obvious reason and without feeling that you want to go? (Q8) \\
Do you leak urine when you are asleep? Q15)
\end{tabular}

Subscale 2: Voiding

Is there are delay before you can start to urinate? (Q12)

Do you have to strain to urinate? (Q13)

Do you stop and start more than once while you urinate without meaning to? (Q14)

\section{Subscale 3: Filling}

During the night, how many times do you have to get up to urinate, on average? Q2)

Do you have to rush to the toilet to urinate? (Q3)

Do you have pain in your bladder? (Q5)

How often do you pass urine during the day? (Q25)

Subscale 4: Sexual

To what extent do you feel that your sex life has been spoilt by your urinary symptoms? (Q22)

Do you leak urine when you have sexual intercourse? (Q24)

\section{Subscale 5: Impact on quality of life}

Do you need to change your outer clothing during the day because of urine leakage? (Q11)

Do you cut down on the amount of fluid you drink so that your urinary symptoms improve, and you can do the things you want to do? (Q26)

To what extent have your urinary symptoms affected your ability to perform daily tasks (eg. cleaning, DIY (do it yourself), lifting objects)? (Q27)

Do you avoid places and situations where you know a toilet is not nearby (eg. shopping, travelling, theatre, church)? (Q28)

Overall, how much do your urinary symptoms interfere with your life? (Q31) 
Table 2: $\quad$ Cronbach alpha results for the five sub-scales of the ICS USI-SF-F at the three data collection points of the study

\begin{tabular}{lcc}
\hline $\begin{array}{l}\text { ICS USI - SF - F } \\
\text { Subscale }\end{array}$ & $\begin{array}{c}\text { Number of } \\
\text { items }\end{array}$ & $\begin{array}{c}\text { Cronbach } \\
\text { alpha scores }\end{array}$ \\
\hline Incontinence symptoms & 5 & 0.76 \\
Voiding & 3 & 0.68 \\
Filling & 4 & 0.52 \\
Sexual symptoms & 2 & 0.88 \\
Impact on quality of life & 5 & 0.78 \\
\hline
\end{tabular}


Table 3: Demographic data, type of incontinence and previous care

\begin{tabular}{|c|c|c|}
\hline Variable & Grouping & No. ${ }^{a}(\%)$ \\
\hline \multirow{2}{*}{$\begin{array}{l}\text { Age } \\
(n=123)\end{array}$} & 65 years and younger & $62(50.4)$ \\
\hline & Over 65 years & $61(49.6)$ \\
\hline \multirow{2}{*}{$\begin{array}{l}\text { Australian born } \\
(n=122)\end{array}$} & Yes & $95(77.2)$ \\
\hline & No & $27(22.0)$ \\
\hline \multirow{5}{*}{$\begin{array}{l}\text { Marital status } \\
(n=119)\end{array}$} & Married / De Facto & $73(59.3)$ \\
\hline & Widowed & $18(14.6)$ \\
\hline & Divorced & $18(14.6)$ \\
\hline & Never married & $4(3.3)$ \\
\hline & Other & $2(1.6)$ \\
\hline \multirow{5}{*}{$\begin{array}{l}\text { Highest level of formal } \\
\text { education }(n=119)\end{array}$} & Primary school & $9(7.3)$ \\
\hline & Secondary school & $63(51.2)$ \\
\hline & Apprenticeship / TAFE & $21(17.1)$ \\
\hline & College & $16(13.0)$ \\
\hline & University & $10(8.1)$ \\
\hline \multirow{5}{*}{$\begin{array}{l}\text { Employment status } \\
(n=122)\end{array}$} & Employed & $22(17.0)$ \\
\hline & Home duties & $16(13.0$ \\
\hline & Retired & $33(26.8)$ \\
\hline & Pension / Benefit & $49(39.8)$ \\
\hline & Other & $2(1.6)$ \\
\hline \multirow{5}{*}{$\begin{array}{l}\text { Living arrangements } \\
(n=119)\end{array}$} & Spouse/partner only & $53(43.1)$ \\
\hline & Alone & $36(29.3)$ \\
\hline & Spouse/partner + children & $20(16.3)$ \\
\hline & Friends/other family & $7(5.7)$ \\
\hline & Other & $3(2.4)$ \\
\hline \multirow{4}{*}{$\begin{array}{l}\text { Type of Incontinence } \\
(n=122)\end{array}$} & Urge & $93(76.6)$ \\
\hline & Stress & $90(73.2)$ \\
\hline & Overflow & $8(6.5)$ \\
\hline & Other & $27(22.0)$ \\
\hline \multirow{8}{*}{$\begin{array}{l}\text { Previous care for urinary } \\
\text { incontinence }^{b} \quad(n=122)\end{array}$} & None & $44(35.8)$ \\
\hline & General medical practitioner & $55(44.7)$ \\
\hline & Specialist medical practitioner & $46(37.4)$ \\
\hline & Physiotherapist & $11(8.9)$ \\
\hline & Hospital & $10(8.1)$ \\
\hline & Other & $5(4.1)$ \\
\hline & Continence nurse advisor & $2(1.6)$ \\
\hline & Home visiting nursing & $1(0.8)$ \\
\hline $\begin{array}{l}\mathrm{d} \\
\mathrm{b}\end{array}$ & $\begin{array}{l}\text { data } \\
\text { nore than one item }\end{array}$ & \\
\hline
\end{tabular}


Table 4: $\quad$ Major Co-Morbidities and Medical History

\begin{tabular}{|c|c|c|}
\hline & Condition $^{b}$ & No. $^{2}(\%)$ \\
\hline \multirow{12}{*}{$\begin{array}{l}\text { General } \\
(n=122)\end{array}$} & Previous UTIs & $67(54.5)$ \\
\hline & Back pain & $37(30.1)$ \\
\hline & Respiratory problems & $26(21.1)$ \\
\hline & Obesity & 19(15.4) \\
\hline & Mobility impairment & 14(11.4) \\
\hline & Other neurological problems & 14(11.4) \\
\hline & Diabetes & $9(7.3)$ \\
\hline & Spinal injury & $6(4.9)$ \\
\hline & Congenital abnormality of the urinary tract & $4(3.3)$ \\
\hline & CA urinary tract & $3(2.4)$ \\
\hline & CVA & $6(4.9)$ \\
\hline & Trauma & $2(1.6)$ \\
\hline \multirow{7}{*}{$\begin{array}{l}\text { Obstetric and gynaecological } \\
(n=122)\end{array}$} & Abdominal hysterectomy & $44(35.8)$ \\
\hline & Babies $>4 \mathrm{Kg}$ & $48(39.0)$ \\
\hline & Vaginal hysterectomy & $12(9.8)$ \\
\hline & Bladder repair & $20(16.3)$ \\
\hline & $>3$ pregnancies & $34(27.6)$ \\
\hline & Assisted delivery & $25(20.3)$ \\
\hline & Pelvic floor repair & $7(5.7)$ \\
\hline
\end{tabular}


Table 5: $\quad$ T-test results comparing those who completed some follow-up data collection with non-completers

\begin{tabular}{|c|c|c|c|}
\hline Variable & Mean (sd) & $\begin{array}{l}\mathrm{t} \text {-test } \\
\mathrm{t}(\mathrm{df})\end{array}$ & $P$ value \\
\hline \multicolumn{4}{|l|}{ Age } \\
\hline Completers & $66(11.8)$ & & \\
\hline Non-completers & $62(12.2)$ & $2.1(120)$ & $0.04^{*}$ \\
\hline \multicolumn{4}{|l|}{ Duration of symptoms } \\
\hline Completers & $11.2(13.9)$ & & \\
\hline Non-completers & $7.5(9.7)$ & $1.7(115)$ & 0.10 \\
\hline \multicolumn{4}{|c|}{ Number of clinic attendances in six months } \\
\hline Completers & $4.1(1.7)$ & & \\
\hline Non-completers & $2.6(1.6)$ & $4.5(121)$ & $<0.0001^{* *}$ \\
\hline \multicolumn{4}{|l|}{ Initial knowledge test score } \\
\hline Completers & $7.4(3.5)$ & & \\
\hline Non-completers & $7.7(2.7)$ & $-0.6(115)$ & 0.53 \\
\hline \multicolumn{4}{|c|}{ ICS USI: urinary symptom subscale } \\
\hline Completers & $7.4(4.1)$ & & \\
\hline Non-completers & $7.8(4.2)$ & $-0.43(118)$ & 0.66 \\
\hline \multicolumn{4}{|l|}{ ICS USI: voiding subscale } \\
\hline Completers & $1.7(2.1)$ & & \\
\hline Non-completers & $1.4(1.8)$ & $0.9(115)$ & 0.38 \\
\hline \multicolumn{4}{|l|}{ ICS USI: filling subscale } \\
\hline Completers & $5.4(1.9)$ & & \\
\hline Non-completers & $5.5(2.2)$ & $-0.29(100)$ & 0.77 \\
\hline \multicolumn{4}{|c|}{ ICS USI: sexual symptoms subscale } \\
\hline Completers & $1.2(1.2)$ & & \\
\hline Non-completers & $1.1(1.6)$ & $0.16(53)$ & 0.87 \\
\hline \multicolumn{4}{|c|}{ ICS USI: impact on quality of life subscale } \\
\hline Completers & $5.9(3.6)$ & & \\
\hline Non-completers & $5.3(3.9)$ & $0.70(91)$ & 0.49 \\
\hline
\end{tabular}

*Significant to the level of $p<0.05$

$* \star$ Significant to the level of $p<0.0001$ 
Table 6: Cross tabulation of those who completed the sexual sub-scale of the USISF-F by age group

\begin{tabular}{|c|c|c|c|c|c|}
\hline & & & \multicolumn{2}{|c|}{$\begin{array}{l}\text { Completed sexual } \\
\text { subscale at Time } 1\end{array}$} & \multirow[b]{2}{*}{ Total } \\
\hline & & & $\begin{array}{l}\text { Did not } \\
\text { complete } \\
\text { sexual } \\
\text { subscale }\end{array}$ & $\begin{array}{c}\text { Completed } \\
\text { sexual } \\
\text { sub-scale }\end{array}$ & \\
\hline \multirow{9}{*}{$\begin{array}{l}\text { Age } \\
\text { groups }\end{array}$} & $30-49$ yrs & Count & 2 & 14 & 16 \\
\hline & & $\%$ within Age groups & $12.5 \%$ & $87.5 \%$ & $100.0 \%$ \\
\hline & & $\begin{array}{l}\text { \% within Completed } \\
\text { sexual subscale T1 }\end{array}$ & $2.9 \%$ & $25.5 \%$ & $13.0 \%$ \\
\hline & $50-69$ yrs & Count & 29 & 34 & 63 \\
\hline & & $\%$ within Age groups & $46.0 \%$ & $54.0 \%$ & $100.0 \%$ \\
\hline & & $\begin{array}{l}\text { \% within Completed } \\
\text { sexual subscale T1 }\end{array}$ & $42.6 \%$ & $61.8 \%$ & $51.2 \%$ \\
\hline & 70-89yrs & Count & 37 & 7 & 44 \\
\hline & & $\%$ within Age groups & $84.1 \%$ & $15.9 \%$ & $100.0 \%$ \\
\hline & & $\begin{array}{l}\text { \% within Completed } \\
\text { sexual subscale T1 }\end{array}$ & $54.4 \%$ & $12.7 \%$ & $35.8 \%$ \\
\hline \multirow[t]{3}{*}{ Total } & & Count & 68 & 55 & 123 \\
\hline & & $\%$ within Age groups & $55.3 \%$ & $44.7 \%$ & $100.0 \%$ \\
\hline & & $\begin{array}{l}\% \text { within Completed } \\
\text { sexual subscale T1 }\end{array}$ & $100.0 \%$ & $100.0 \%$ & $100.0 \%$ \\
\hline
\end{tabular}


Table 7: $\quad$ Repeated measures ANOVA results for urinary symptom sub-scales, and knowledge over time

\begin{tabular}{llll}
\hline Variable & $\mathbf{F}$ & $\mathbf{d f}$ & P value \\
\hline Knowledge test score & 20.4 & 2 & $<0.0001$ \\
\hline ICS USI: urinary symptom subscale & 21.7 & 2 & $<0.0001$ \\
\hline ICS USI: voiding subscale & 4.6 & 2 & 0.014 \\
\hline ICS USI: filling subscale & 7.3 & 2 & $<0.001$ \\
\hline ICS USI: sexual symptoms subscale & 0.7 & 2 & $0.51^{*}$ \\
\hline ICS USI: impact on quality of life subscale & 15.3 & 2 & $<0.0001$ \\
\hline Knowledge test score & 20.4 & 2 & $<0.0001$ \\
\hline
\end{tabular}

* Not significant at 0.05 level 
Figure 1: $\quad$ Line graph of mean USI subscale scores at initial consultation (T1), three months (T2) and six months (T3)

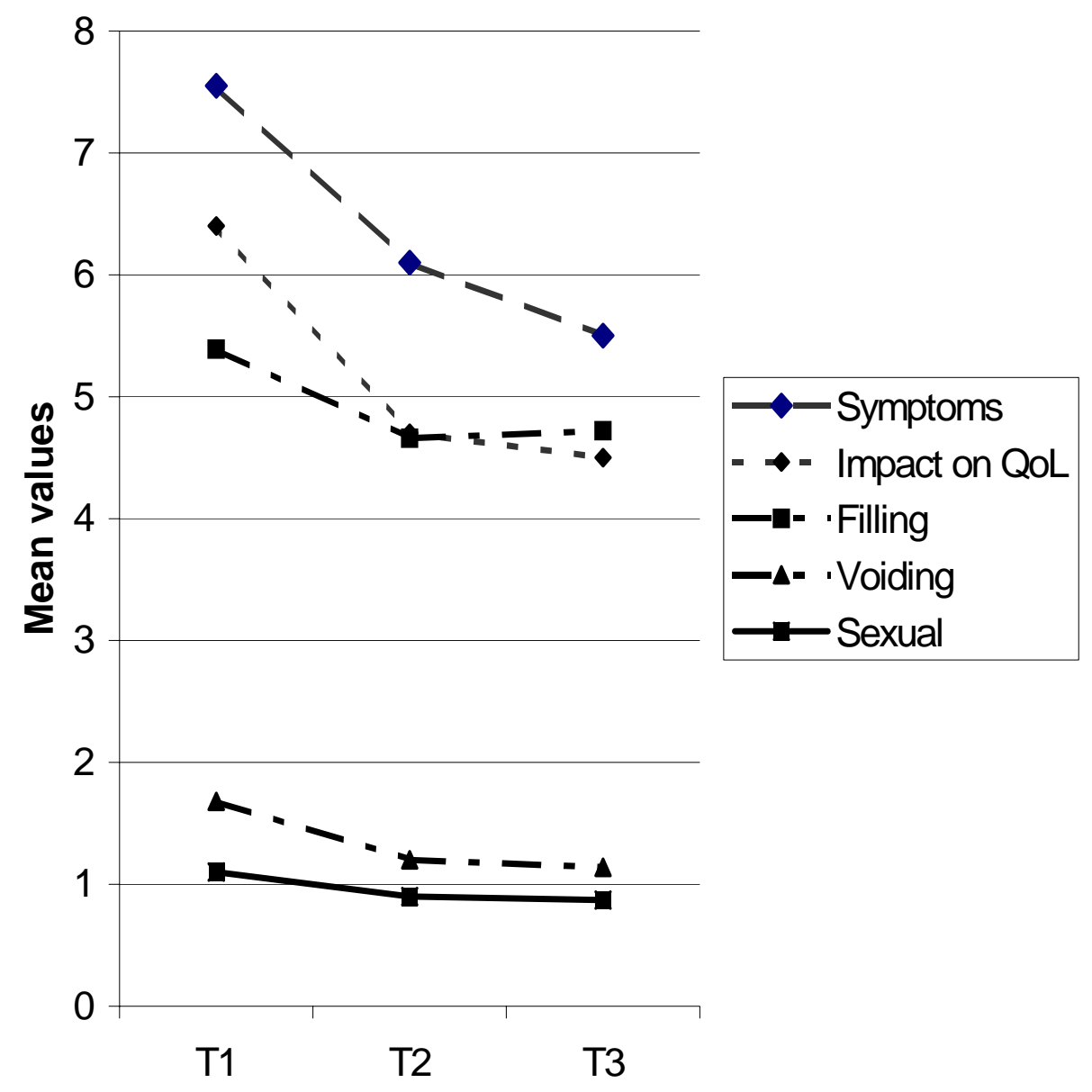


Figure 2: $\quad$ Line graph of mean knowledge scores at initial consultation (T1), three months (T2) and six months (T3)

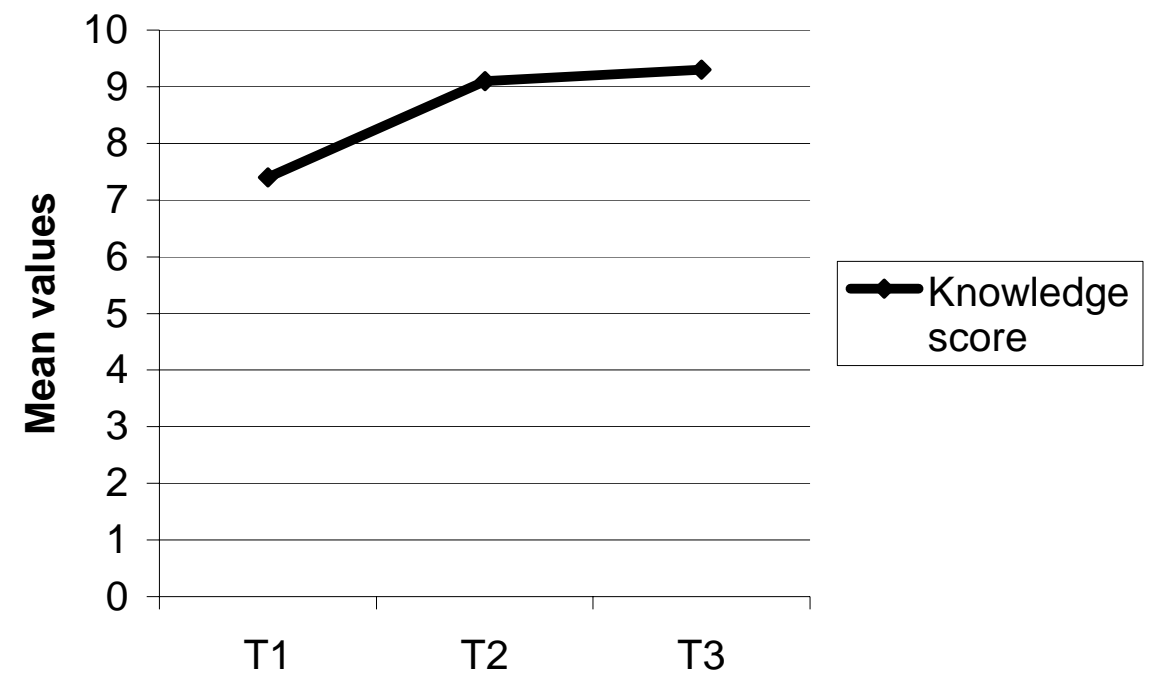




\section{References}

American Medical Directors Association. (1996 [reviewed Jan 2001]). Urinary incontinence. National Guideline Clearinghouse. Retrieved 15-9-03, 2003, from the World Wide Web: http://www.guideline.gov/summary/summary.aspx?doc_id=1812\&nbr=1038\&string=inco ntinence

Australian Bureau of Statistics (2003) Cat. No. 3218.0. ABS, Canberra.

Borrie, M.J., Bawden, M., Speechley, M., \& Kloseck, M. (2002). Interventions led by nurse continence advisers in the management of urinary incontinence: A randomised controlled trial. Canadian Medical Association Journal, 166(10), 1267-1273.

Burgio, K.L., Locher, J.L., Roth, D.L., \& Goode, P.S. (2001). Psychological improvements associated with behavioural and drug treatment of urge incontinence in older women. Journal of Gerontology, 56B(1), 46-51.

Chiarelli, P., Bower, W., Wilson, A., Sibbritt, D., \& Attia, J. (2001). The prevalence of urinary incontinence within the community: A systematic review. Department of Health and Ageing, National Continence Management Strategy. Retrieved 3-4-03, 2003, from the World Wide Web: http://www.continence.health.gov.au/ncms/ncmseuai.htm

Dugan, E., Cohen, S.J., Bland, D.R., Preisser, J., Davis, C.C., Suggs, P.K., \& McGann, P. (2000). The association of depressive symptoms and urinary incontinence among older adults. JAGS, 48(4), 413-416.

Fultz, N.H., \& Hersog, A.R. (2001). Self-reported social and emotional impact of urinary incontinence. JAGS, 49, 892-899.

Gold Coast City Council. (2004) Population issues. City Facts, 1. Gold Coast City Council, Evandale.

Jackson, S., Donovan, J., Brookes, S., Eckford, S., Swithinbank, L., \& Abrams, P. (1996). The Bristol Lower Urinary Tract Symptoms Questionnaire: Development and psychometric testing. British Journal of Urology, 77, 805-812.

Johnson, T.M., Kincade, J.E., Bernard, S.L., Busby-Whitehead, J., Hertz-Picciotto, I., \& DeFriese, G.H. (1998). The association of urinary incontinence with poor self-rated health. JAGS, 46, 693-399.

Lewey, J., Billington, A., \& O'Hara, L. (1997). Conservative treatment of urinary incontinence. Nursing Standard, 12(8), 45-47. 
Liberman, J.N., Hunt, T.L., Stewart, W.F., Wein, A., Zhou, Z., Herzog, A.R., Lipton, R.B, \& Diokno, A.C. (2001). Health-related quality of life among adults with symptoms of overactive bladder: Results from a U.S. community- based survey. Urology, 57(6), 1044-1050.

McDowell, B.J., Engberg, S., Sereika, S., Donovan, N., Jubeck, M.E., Weber, E., \& Engberg, R. (1999). Effectiveness of behavioral therapy to treat incontinence in homebound older adults. JAGS, 47(3), 309-318.

McGhee, M., O'Neill, K., Major, K., \& Twaddle, S. (1997). Evaluation of a nurse-led continence service in the southwest of Glasgow, Scotland. Journal of Advanced Nursing, 26, 723728.

Meade-D'Alisera, P., Merriweather, T., Wentland, M., Fatal, M., \& Ghafar, M. (2001). Depressive symptoms in women with urinary incontinence: A prospective study. Urologic Nursing, 21(6), 397-399.

O'Brien, J., Austin, M., Parminder, S., \& O'Boyle, P. (1991). Urinary incontinence: Prevalence, need for treatment, and effectiveness of intervention by nurse. British Medical Journal, $303,1308-1312$.

Peake, S., \& Manderson, L. (2003). The constraints of a normal life: The management of urinary incontinence by middle aged women. Women \& Health, 37(3), 37-51.

Roe, B., \& Doll, H. (2000). Prevalence of urinary incontinence and its relationship with health status. Journal of Clinical Nursing, 9, 178-188.

Sampselle, C.M. (2000). Behavioral intervention for urinary incontinence in women: Evidence for practice. Journal of Midwifery \& Women's Health, 45(2), 94-103.

Seim, A., Siverstsen, B., Eriksen, B.C., \& Hunskaar, S. (1996). Treatment of urinary incontinence in women in general practice: Observational study. British Medical Journal, 312(7044), 1459-1463.

St John, W., Wallis, M., \& James, H. (2002). Making links: Evaluation of an integrated multidisciplinary community-focussed model of service delivery for inter-sectoral transition and community support for people suffering urinary incontinence in the Gold Coast region [Final Report to the Department of Health and Ageing]. Faculty of Nursing and Health, Griffith University. Retrieved 3-7-2003, from the World Wide Web: http://www.continence.health.gov.au/ncms/waterworx.htm. 
St John, W., Wallis, M., James, H., McKenzie, S., \& Guyatt, S. (2004, in press). Targeting community-dwelling urinary incontinence sufferers: A multi-disciplinary communitybased model for conservative continence services. Contemporary Nurse, 18, 1-2.

Swithinbank, L.V., \& Abrams, P. (1999). The impact of urinary incontinence on the quality of life of women. World Journal of Urology, 17(4), 225-229.

Williams, K.S., Assassa, R.P., Smith, N. K. G., Jagger, C., Perry, S., Shaw, C., Dallosso, H., McGrother, C., Clarke, M., \& Brittain, K. R. (2000). Development, implementation and evaluation of a new nurse-led continence service: A pilot study. Journal of Clinical Nursing, 9, 566-573.

Wyman, J.F. (1998). Quality of life of older adults with urinary incontinence. JAGS, 46(6), 778780. 